\title{
MOLECULAR MEDICINE SOCIETY: A GREAT START, A GREAT FUTURE ${ }^{1}$
}

\author{
David G. Nathan, M.D. \\ President, Dana-Farber Institute of Cancer Research and \\ President, Molecular Medicine Society
}

This meeting ${ }^{2}$ is truly a great start. You can hear this in the terrific papers presented during the plenary sessions. The future of our science is remarkable, but, as Floyd Bloom ${ }^{3}$ said a little earlier, there are problems that we have to deal with in a forthright way. In dealing with them, however, it is very important not to get depressed; after all, for Ken Warren and me this is an incredible moment. Forty-five years ago we entered Harvard Medical School, and we spent our time staring down old microscopes at the same tissue sections and discovered one thing. We discovered that DNA is blue, or at least the nucleus is blue. As we were coming to that brilliant conclusion, James Watson, a graduate student from the University of Indiana, was on his way to Harvard by a circuitous route that brought him to Francis Crick's laboratory in the other Cambridge, where the molecular medicine revolution, which was begun by Avery, McCarty, McLeod, and others, was vastly accelerated. Ken and I were absolutely blissfully unaware of all of that.

Four years later, I found myself walking in the somnambulistic state of a Peter Bent Brigham Hospital ${ }^{4}$ intern in the company of one of my brilliant junior residents, a fellow named Stanley Yachnin, now a professor of medicine at the University of Chicago. "Do you know something?" queried Stanley. "Very little," was my exhausted and annoyed reply. "Do you know,"

\footnotetext{
${ }^{1}$ This editorial was adapted from a speech given on May 3, 1996, at the first annual meeting of the Molecular Medicine Society.

${ }^{2}$ The first annual meeting of the Molecular Medicine Society.

${ }^{3} \mathrm{Dr}$. Floyd Bloom gave a speech at the same meeting, which was published as an editorial in the July 1996 issue of Molecular Medicine.

${ }^{4}$ Now the Brigham and Women's Hospital (Boston, MA).
}

went on Stanley without listening to me (he never did), "I'll bet you if you link three or four DNA bases together they could spell out a specific amino acid." I heard him and my gorge rose high enough to push my ennui away. "Stanley, stop that drivel. Let's go into the ward and get the i.v.'s and cultures done." Once again, the molecular medicine revolution had eluded me. At that moment Ken Warren was an intern at Boston City Hospital where he also spent much of the day starting i.v.'s and culturing body fluids. We were scarcely revolutionaries.

At that time another revolution was under way here in Washington, a change that would alter our landscape. That revolution was fueled by the massive infusion of federal funds into biomedical research. Total private and public contributions to our field grew from 45 million dollars in 1940 to 16.2 billion dollars in 1987, a 42-fold increase in costs and dollars. Between 1950 and $1965, \mathrm{NIH}$ funding grew at a rate of $9 \%$ per year and a critical funding distribution decision was made: Grants would be awarded by an individual peer review mechanism rather than by institutional selection. That decision led to massive expansion in the biomedical research enterprise and inevitably to the problems and the successes that face us today. The successes are obvious, and they are right here in this meeting. The problems can be stated quite simply, as Floyd emphasized them. Just as our molecular medicine revolution is about to go to the clinic, we find government and foundation funding for translational research in short supply.

How can this be? We have already accomplished so much in our initial translational efforts, due largely to the work of David Weatherall and his colleagues, and to a number of investigators worldwide, including Haig Kazazian, Stuart Orkin, and Y. W. Kan. One or two 
decades ago we worked out a molecular basis of hemoglobinopathies and established prenatal diagnosis for sickle cell anemia and thalassemia, two major scourges of the less and the underdeveloped world. With those techniques, we were able to nearly eradicate new cases of thalassemia in Sardinia, Greece, and elsewhere. The techniques, if widely applied, could have provided enormous relief to burdened pediatric and blood bank budgets throughout the old malarious world. But, such a record is behind us. Today remarkable studies of gene sequence and expression promise to provide us with the tools to define the genetic basis of all the inherited diseases and cancer. Why, therefore, do we now find ourselves in a crisis characterized by what we appreciate as dwindling support for translational research, the research that is so necessary if we are to apply the fruits of our basic knowledge for the better of individuals and communities throughout the world?

Fortunately, we have not yet sacrificed the fundamental source of clinical or translational research: our basic biomedical research grant program. It has continued to grow, albeit slower than in the past. That is fortunate because we all agree that appropriate public funding of basic research by the individual peer review mechanism is absolutely required if translational clinical research is to occur at all. Indeed, the union of basic and clinical research is the reason for the founding of our Society. The Molecular Medicine Society recognizes that joining excellent highpriority basic and clinical science is central to the success of our revolution. I estimate that one has to perform at least a hundred basic experiments in order to stumble on one that can make it to the clinic, and no one can predict where the best basic research will be undertaken. Brilliant ideas may emerge anywhere. Hence, the commitment to individual peer review should continue to characterize foundation and NIH funding decisions in basic research.

Though the future of basic research, I insist, is bright, this approach makes life in the field tough and very competitive because the new biology has attracted so many minds, many of them right in this room. Postdocs, therefore, worry that they will not be able to start their laboratories after they finish their training experience. That is a valid worry because there is room only for a population of a given size in this fascinating field. I don't think we will fix that very well unless funding is to accelerate far beyond what we consider feasible. As a result, the peer review system will continue to select the very best, and only the very best will flourish. In this respect, these are the best and the worst days of biomedical basic science. Best because the power of molecular biology is so tremendous that we can do experiments that were absolutely unheard of only a decade or so ago. Worst because the very power of these experiments has attracted so many brilliant young people that there simply may not be room for all of them as permanent members of the field. This is in some way similar to the desire of young military officers to be pilots, an endeavor for which many volunteer but few are chosen. But, that is exactly why the future of our field is so very bright: The best want to be in it.

Clinical research presents a somewhat different problem because productive clinical research, particularly complex translational research, requires an institutional infrastructure that will encourage and support the process. NIH has recognized that fact by limiting the number of clinical research centers that it supports in the United States to about one-half of the nation's medical schools. The General Clinical Research Center (GCRC) Program, however, cannot possibly support all of the financial needs of clinical research in the seventy or so GCRCs that are funded. The academic medical centers that house GCRCs have relied on clinical income to fund most of their activities, and that income is now becoming a threatened species as managed care and insurance companies ratchet down their reimbursements. Furthermore, that shrinking pool of dollars is spread around an academic medical establishment that grew massively during the days of charged reimbursements and of easily acquired grants. We now face a shrinkage process that could, if we are not careful, carry away some of the very best clinical investigation units that staff our revolutionary army.

Finally, some insurance companies, which are interested in immediate profit and not in the future, are denying access to research projects by their customers. This is being vigorously opposed by the National Cancer Institute, which is seeing to it that all patients with military insurance, and possibly others as well, will be available for NCIapproved protocols. This may push the private insurance companies towards a different view. Until they are persuaded, however, pharmaceutical manufacturers will increasingly utilize extra-academic contract research organizations rather than academic health centers for the development of the exciting by-products of our 
revolution. If this trend continues unchecked, we in this room will lose control over the clinical trials that are the desired fruits of our laboratory labors.

Concurrent with these trends, the public/ private foundation partnership, upon which we depend to do the translational research that will carry newly acquired molecular information from the bench to the bedside, increasingly relies on charitable donations. This is a fact that defies logic because private philanthropies' share in medical research has fallen from nearly $40 \%$ in 1940 to less than $10 \%$ today. For private philanthropies to shoulder the doubling or tripling of their contributions that will be necessary to replace the former contributions of insurers is an enormous and possibly intolerable burden. Another important source of funds is industry, and the entrepreneurs among us have fared very well with that source. There are conflicts of interest in industrial/academic relationships, but these can be controlled. Industry's contribution, though somewhat small now (but very large a few years ago), is vital and must be increased.

Harold Varmus, the Director of NIH, is as devoted to molecular medicine as any leader at NIH has ever been. He has developed an advisory panel on clinical research with the charge to recommend the steps that must be taken if our molecular medicine revolution is to prosper in the clinic. Our panel has met for a year, and in two weeks it will meet to review tentative recommendations from the various subcommittees. I cannot tell you right now precisely what those recommendations will be, but I can promise you that the panel is totally committed to the progress of the molecular medicine revolution. It has been constituted, not only to advise on the best methods to insure this progress, but also to remain in office, as it were, to implement its recommendations.

We must, however, accept the fact that the continuous growth of clinical research that Ken Warren and I have observed from the time of our graduation in 1955 to the present will slow down. If investor-owned research corporations are not to take over the national clinical research effort, our revolution will have to be consolidated. We must focus our clinical research in those large, well-funded academic health centers that can deliver on the enormous but complex promises of molecular medicine. This means that some institutions will be disappointed because they will not be able to participate in this exciting activity.

Basic research, which depends on bright individuals and less on institutional resources, probably has room for measured growth and a wider range of sites of the activity. But, I fear that we will need to find better ways to redirect our R01 budget, perhaps by using grants that pay less overhead recovery to support investigators in institutions at which research budgets are lower than a given level. These, I know, may represent tough and terribly unacceptable compromises, but we need to make some of them if we are to continue to lead the way in clinical and basic biomedical research.

Despite these cautionary comments I remain absolutely confident that the major goals of the Molecular Medicine Society, which are to plumb the roots of molecular biology in human disease and bring the fruits of the molecular medicine revolution to the bedside, will be realized and that our Society will be in the exciting vanguard of that enterprise. This, our first meeting, is a small beginning of what will become a torrent of new information that will inevitably bore through mountains of ignorance and bring new growth of clinical investigation on behalf of patients with presently intractable genetic disease and malignancy. Our commitment to those patients, whether our degrees say Ph.D. or M.D. on the parchment, characterizes our Society and makes me proud to present this: our first presidential report. Thank you for being my fine colleagues. 